DÜMF Mühendislik Dergisi

\title{
Dicle Üniversitesi Güneş Enerji Santralinin Şebeke İle Paralel Çalışmasında Olası Adalaşma Probleminin Matlab Simülasyon Ortamında Değerlendirilmesi
}

\author{
Sadi Serdar GÜNELI' \\ Dicle Üniversitesi, Elektrik Elektronik Mühendisliği Bölümü, Diyarbakır \\ ssguneli@dicle.edu.tr ORCID 0000-0003-2618-9035, (412) 2411000 (5960) \\ Muhammet Ali ARSERIM \\ Dicle Üniversitesi, Elektrik Elektronik Mühendisliği Bölümü, Diyarbakır \\ marserim@dicle.edu.tr ORCID 0000-0002-9913-5946, (412) 2411000 (0000)

\section{Rıdvan KENANOĞLU} \\ Dicle Üniversitesi, Bilgisayar Teknolojileri Bölümü, Diyarbakır \\ ridvan.kenanoglu@dicle.edu.tr ORCID 0000-0002-4480-1657, (412) 2411000 (7839)
}

Geliş: 26.06.2019, Revizyon: 28.06.2019, Kabul Tarihi: 08.08.2019

\section{$\ddot{\mathbf{O} z}$}

Türkiye'de Elektrik Piyasasında Lisanssız Elektrik Üretimine İlişkin yönetmenlik; 14/3/2013 tarihli ve 6446 sayılı Elektrik Piyasası Kanununun 14 üncü maddesi kapsamında değiştirilmesi ile Ülkemizde bir çok yerel elektrik santrali kurulmuş ya da kurularak elektrik şebekeleri ile paralel çalışır duruma getirilecektir. Yapılan son kanun değişiklikleri ile birçok yerel elektrik santralinin kurulması ve işletmeye alınması işlemleri devam etmektedir. Bu santrallerin enerji üretimine büyük katkısının yanında şebeke ile paralel çalışması sırasında teknik personel ve diğer tüketiciler açısından çeşitli problemler doğurmaktadır. Bu çalı̧̧mada öncelikle, Dicle Üniversitesi Güneş Enerji Santralinin Ana Şebeke ile bağlantısı Matlab simülasyon ortamında modellendikten sonra olası arızalara karşı elde edilen veriler gözlemlenmiştir. Daha sonra Ana Şebeke ile paralel çalışan Santralin, Mühendislik Fakültesini beslemesi durumunda oluşacak farklı senaryolar simülasyon ortamında tasarlanmıştır ve bu simülasyonların sonuçları değerlendirilmiştir.

Anahtar Kelimeler: Dağıtık Üretim, Adalaşma, Rocof, Bireysel Yerel Santral.

\footnotetext{
* Yazışmaların yapılacağı yazar
}

DOI: $10.24012 /$ dumf. 582580 


\section{Giriş}

Günümüzde, nüfus artışı ve elektrik-elektronik teknolojisindeki gelişmeler dünyada ve ülkemizdeki toplumların elektrik enerjisine olan bağımlılığını artırmaktadır. Fosil yakıtların tükeniyor olması ve çevre sorunları oluşturması, dünyadaki bütün ülkeleri alternatif enerji kaynaklarını kullanmaya teşvik etmiştir. Yaşanan bu gelişmeler geleneksel elektrik enerji sitemlerinin yeniden yapılandırılmasina sebep olmuştur.

Elektrik enerjisi büyük güçlerde, şehir merkezlerinin dışında üretilmesi sebebiyle, en az kayıpla enerji iletim sistemleri yardımıyla merkeze taşınmak zorunda bırakılmıştır. Sanayiciler enerji kalite ve arıa problemlerinden dolayı bireysel yerel santrallerini kurmuşlardır( Powell L J 1988) ( (Warin J W 1990). Lokal santrallerden elde edilen elektrik enerjisinin maliyetinin yüksek olması nedeniyle aynı kaynağ hem de elektrik enerjisi üreten CHP (Combine Heat and Power) teknolojisi ile düşürmeye çalışmışlardır( Powell L J 1988) (Woodworth M 1996). Devletlerde özellikle nüfusun yoğun olduğu yerlerde bu santralleri tercih etmişlerdir.

Üniversitelerde yapılan araştırmalar ve gelişen röle teknolojisi Bireysel Yerel Santrallerin (Embedded Generation) geleneksel enerji sitemine bütünleşmiş ( entegre ) çalışmasını sağlamıştır. Böylece düşen enerji maliyetleri bir anda Lokal Santrallerden elektrik enerjisi üretimini teşvik etmiştir..

Yenilenebilir enerji kaynakları fosil yakıtlara alternatif bir kapasiteye sahip olmasına karşın elektrik enerjisi üretme maliyetlerinin yüksek olması ve büyük güçlerde enerji üretmenin zor olmas1 nedeniyle piyasada istenilen talebi oluşturmuyordu. Ana şebekeye entegre edilen Bireysel Yerel Santraller Yinelenebilir Enerji Kaynaklarının enerji üretim maliyetini düşürmesi ve yapılan araştırmalar sonucu özellikle Güneş Enerjisi ve Rüzgar Enerjisinden daha verimli enerji elde edilmesiyle tüm dünyada Yinelenebilir Enerjinin kullanılmasının önünü açmıştır. Ülkemizde, yinelenebilir enerjinin en önemli kaynaklarından biri, solar sistemlerdir.

Yinelenebilir enerjiden geleneksel enerji üretim sistemleri ile kıyaslandığında küçük güçlerde elektrik enerjisi üretilse de, bu sistemlerin, tüketim merkezlerinin yakınında elektrik enerjisi üretmesi ve gelişen röle teknolojisi ile elektrik dağıtım sistemlerine bütünleşmiş (entegre) çalışması sayesinde elektrik enerji iletim sistemlerinde önemli değişikliklere neden olmuştur.

Bu makalede, Dicle Üniversitesi Güneş Enerji Santralinin Ana Şebeke ile paralel çalışması neticesinde oluşabilecek arızalarda adalaşma matlab simülasyon programında oluşturulmuş ve öneriler sunulmuştur.

\section{Materyal ve Yöntem}

\section{Dağıtılmış Üretim Nedir?}

Dağıtılmış Üretim(DÜ), (DG) veya Embedded Generation (Geleneksel sisteme gömülü entegre Bireysel Yerel Üretim Santralleri) sayılarının fazlalığı ve bağlantı noktaları dolayısı ile geleneksel şebeke sistemi ile bağlantılı bir kavramdır. Bireysel yerel üretim santralleri bağlantı noktalarında Ana şebeke ile paralel bağlanarak geleneksel sistemin aksine çift taraflı yük akışına olanak tanımanın yanında enterkonnekte sistemin bir parçası haline gelen Dağıtık Üretim santralleri olarak tanımlanırlar. $\mathrm{Bu}$ konsepti sürdüren Bireysel Yerel Üretim Santrallerine; Dağıtık Üretim Santralleri (Distributed Generation) (DG) olarak tanımlanır (Şekil 1). Bir kaç kilovat KW gücünden onlarca megavat MW güce kadar elektrik enerjisi üretme kabiliyeti olan küçük ölçekli generatörler ana şebeke ile dağıtım veya trafo istasyonu seviyesinde dahil olurlar (Bergen A.R. and Vittal V 2000) (Engineering Recommendation G59/1, 1985). 


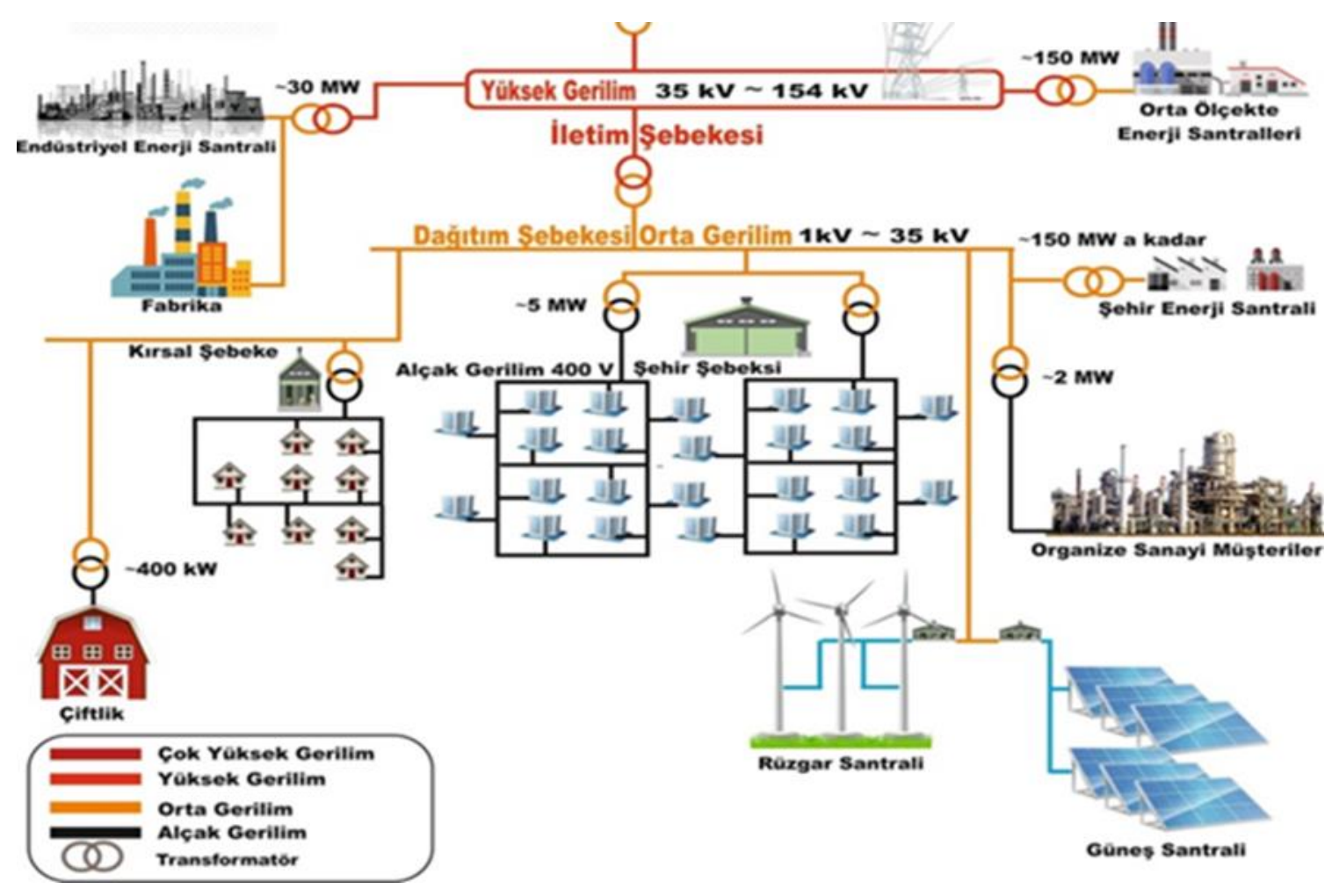

Şekil 1 İletim ve dağıtım seviyesinde dağıtık enerji santrallerinin şebekeye entegresi

Dağıtık Üretim (DG) 5 kW'tan daha küçük güçlerden 25,000 kW'a kadar bazen daha büyük türbinlere ve dizel jeneratörlere kadar farklı güçlerde olabilmektedir. $25,000 \mathrm{~kW}$ seviyesi genellikle en üst aralık olarak kabul edilmektedir. $\mathrm{Bu}$ aralık küçük, orta ve büyük bireysel üretim santralleri olarak incelenmektedir (Jenkins N 1995) ( Bergen A.R. and Vittal V 2000). Büyük güçte olanlar kapasite olarak $1000 \mathrm{~kW}$ ile $10,000 \mathrm{~kW}$ arasındaki dizel jeneratörlerdir. Bazı santraller y1l boyunca ana üretim santrali olarak tasarlanmışken bazıları sadece enerjiye yoğun ihtiyaç duyulduğu zamanlarda kullanılmaktadırlar (Muller L. ve ark. 1990). Büyük güçte olanlar genelde sanayi bölgelerindeki fabrikalar için ve/veya enerji dağıtım sistemine özel üretim yaparak katk1 sunan bireysel yerel santraller olarak tasarlanmıştır. Küçük güçte olanlar ise bireysel evler ve küçük işletmeler gibi yoğun dağınık uygulamalar için tasarlanmıştır (Koeppel G.
2003). Aralıkları $1500 \mathrm{~kW}$ ile $5000 \mathrm{~kW}$ arasındadır. Bu tip santraller dağıtım şebekesi ile paralel çalıştığında gerilim ölçümleri daima müşteri tarafında yapılır. Bir evin tüm ihtiyacı veya bir işletmenin bazı ihtiyaçlarını karşılamak üzere bu sistemler tasarlanır (Mozina C.J. 2001) (Hodgkingson. G. 1998)

DG uygulamalarında Güneş fotovoltaik (PV), dizel motorlar, gaz türbinleri, biokütle, küçük hidroelektrik jeneratörler, rüzgâr tribünleri gibi çok çeşitli üretim teknolojileri kullanılmaktadır (Guo-Kiang Hung, et al). Bazı DG üniteleri doğal gazdan ve petrolden elektrik enerjisi üretmekle birlikte atık enerjiyi 1s1 enerjisine çevirerek ısınma amaçlı kullanır co-generation (Jenkins N. 1995) (Ackermann T. and Knyazkin V) (Ye. Z. et al 2003) 


\section{Dağıtık Üretim Santrallerinin Ana Şebekeye Entegre Edilme Sebepleri}

Dağıtık güç sistemleri kamu veya bireysel müşteriler tarafından işletilebilir enerji güç sistemlerine birçok yönden katkı sunabilir. Dağıtık üretim tesisleri enerji maliyetlerini düşürmenin yanında sistem güvenirliğini artırabilir. Bununla birlikte çevre kirliliğini azaltırken enerji kalitesinin artmasına sebep olur (Burton T. et al. 2001) (Dugan. R.C. and McDermott. T.E. 2001).

Geniş çaplı elektrik kesintisi olduğunda lokal yükler DÜ' lerden beslenmeye devam edeceği için, lokal yükler için enerji sürekliliği sağlanmış olur. Fakat ana şebekeden ayrılan her Bireysel Yerel Santral bir güç adası oluşumuna sebep olur. $\mathrm{Bu}$ durum adalaşma (Islanding) olarak tanımlanır. $\mathrm{Bu}$ durum bireysel yerel santrallerin lokal yükleri besleyeceği yeterli üretime sahip olmasının yanında dağıtım sisteminin kontrol eden sitemin yeterli olmasını gerektirir (Öhrström. M. 2003). Farklı kaynaklar kullanılarak üretim yapan jeneratörlerin yakıt seviyelerinin sınırlı olması veya yeterli güvenlik seviyesine sahip olmaması başarılı adalaşma çözümlerine rağmen DÜ' lerin istenilen faydayı sağlamasına engel diğer bir olasılığg olușturur (Kashem M.A. and Ledwich. G 2002) ( Fickert. L. 2003).

Hizla artmakta olan elektrik enerji ihtiyacinı DÜ' lerden sağlamak lokal yüklere yakın olması nedeniyle gerek kamu gerekse özel üreticiler tarafindan yapılan yatırımların maliyetlerinde ciddi avantajlar elde edilir. Yerel santraller lokal yüklere yakın olması nedeniyle enerji kayıplarının azalmasında katkı sunar (Ye Z. et al. 2003 ).

Amerika'da yeni neslin eski nesille değiştirilmesi durumunda $\% 30$ değişikliğin devletin enerji kaybını \% 15 azaltacağ tahmin edilmektedir. Y1lda altı milyar kilovat-saat enerji tasarrufuna karşılık gelmektedir (Bergen A.R. and Vittal. V. 2000 ). Diğer taraftan bireysel yatırımcıların kendi tesisleri kurmaları devletin karını düşürmekle beraber yatırımcılarına uzun vadeli enerji maliyeti istikrarı ve bazı durumlarda tasarruf sağlar. (Bergen A.R. and Vittal V. 2000). Güneş enerjisi kaynak olarak kullanılırsa çevre kirliliğinin azalmasına büyük katkı sunar. Kesintisiz enerji sağlayan DÜ' ler kırpışma, voltaj regülasyonu gibi sorunları çözerek enerji kalitesinin artmasını sağlar(Tran-Quoc T., 2000).

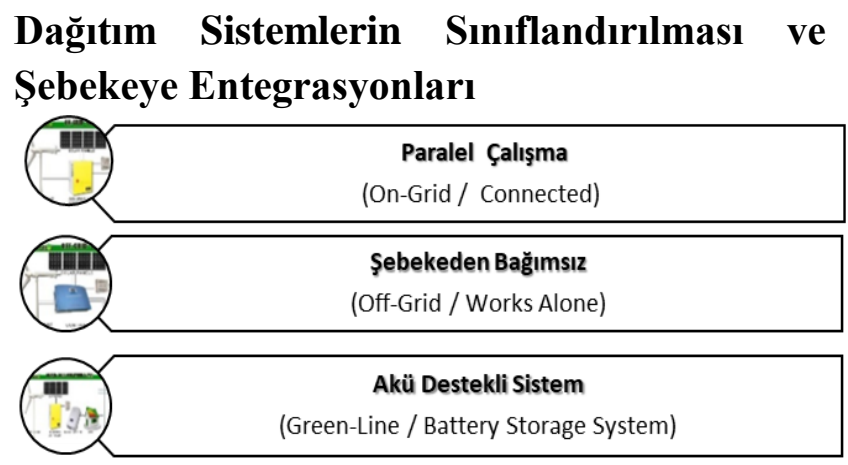

\section{Şekil 2-Dă̆ıtık Üretim Sistemlerin Sinıflandırılması}

Şekil 2'de görüldüğü gibi Bireysel Yerel Santrallerin gruplandırılması ve Ana şebekeye gömülmesi, paralel çalışması Şebeke Destekli ve Şebekeye Paralel DG sistemleri tarafindan oluşturulacak besleme entegrasyonları, olası sorunları gündeme getirmektedir. Birleştirme, entegre öncesi bu sorunların tespit edilmesi, sistem işletmecisine, bireysel yerel santral tesisi sahibine ve dağıtım kısmındaki kullanıcılara önemli katkılar sağlayacaktır. Sorunların saptanması tasarlanmış sistem analizleri yolu ile tespit edilmelidir. DG' nin hangi noktadan dağıtım sistemine entegre edilmesi gerektiği, gerilim ve güç kontrolünün nasıl tespit edilmesi gerektiği, kırpışma ve harmonik etkiler varsa bunların nasıl engellenebileceği, üretim santrallerinin tesisin bağlandığı kısımda oluşturacağı kısa devre katkısı ve sisteme etkileri bu analizler yolu ile belirlenip, gerekli önlem ve çözümler üretilmelidir.

\section{DG' lerde Adalaşma (Islanding)}

Dağıtılmış senkron jeneratörlerin koruma sistemleri mutlaka adalaşma durumunu tespit etmeli ve ana şebeke koruma kurallarını yerine getirmelidir. Dağıtık jeneratörler herhangi bir 
arıza meydana geldiğinde ana şebekeden ayrılarak adalaşma durumunu oluşturur. Adalaşma meydana geldiğinde bireysel yerel santraller enerji üretmeye devam etmekte olduğu için hatlarda enerji akışı devam etmektedir. $\mathrm{Bu}$ durum ana şebekenin kaybı olarak bilinir (Loss of Main) (Jenkins,2000) (Bergen, Vital, 2000) (Muller, Boog, 1990). Lokal hatlara ana şebekeden akan yük akışı durmasina karşın sistem lokal jeneratörler tarafından beslenmeye devam etmesi çeşitli güvenlik risklerine sebep olur. Sistemde enerji olması hattı onarmaya gelecek olan personel için hayati risk oluşturmasının yanı sıra, sistemdeki arıza kalitesinin düşmesine ve lokal jeneratör ve yüklerin zarar görmesine sebep olur. $\mathrm{Bu}$ riskleri en aza indirmek için gerekli koruma sistemi hemen devreye girip adalaşmayı engellemelidir.

Bugüne kadar yapılan uygulamalarda adalaşma 200-400 ms arasında tespit edilmesi gerekliliği saptanmıştır. Bu koşulları yerine getirmek için her dağıtılmış Bireysel Yerel Santrali buna uygun bir koruma sistemi ile donatılmalıdır. Vektör dalgalanma (gerilim değişim oranı tespit) röleleri bu amaç için kullanılmaktadır. (Dispersed Generation, CIRED Working Group 4, 1999), (Jenkins $N$ ve arkadaşları 2000) (Embedded Generation, London, 2000). Bu röleler sanayide büyük kabul görmüştür.

Tüm dağıtılmış senkron jeneratörler röle üreticilerinin tavsiyelerine ve elektrik şebekesinin frekans açma kurallarına göre yapılır (IEEE standart, 2003). Vektör dalgalanma ve frekans röleleri sistem frekans sapması koşulunda çalıştığı için rölelerden sadece biri kullanılarak koruma sistemi dizayn edilirse özellikle küçük güçteki jeneratörlerin korumasında ciddi tasarruf sağlanmış olur ve koruma sistemi oldukça basit hale gelir.

Diğer önemli bir sorun röle koruma gerekliliğindeki çelişkilerdir. IEEE standartları küçük voltaj değişikliklerinde DG' nin bağlantısının kesilmemesini önerir (IEEE standard, 2003). Röle bu gereksinmeleri karşılayacak şekilde ayarlanmışsa adalaşma koşullarını istenen sürede tespit edemeyebilir.
Diğer yandan röle hassas ayarlanmışsa küçük frekans değişikliklerinden dolayı DG' yi açtırabilir.

\section{Güç Sistem Koruması}

Temel güç sistemi koruma ilkeleri ve standartları literatürlerde belirtilmiştir (Bergen, Vital, 2000) (Muller , Boog, 1990). Güç sistemi korumasının temel amacı güç sistemlerinin güvenli çalışmasını, yani insanların, personelin, ekipmanın güvenliğini sağlamaktır. Bununla birlikte kaçınılmaz hataların sistemdeki etkisini en aza indirmektir. Elektriksel açıdan tehlikeli durumlar oluşabilir.(Geidl, 2005)

- Aşırı akımlar

- Aşırı gerilimler.

Örneğin; şebekelerin eş zamansız eşleşmesi (senkronize olmaması) yüksek akımlara neden olur.

Toprak arızaları yüksek dokunma voltajlarına neden olabilir ve bu nedenle insanların yaşamlarını tehlikeye sokabilir.

Genel sorun daima gerilim ve/veya akımın limit dışı olmasıdır.

$\mathrm{Bu}$ nedenle, güç sistemlerinin güvenli bir şekilde çalışmasını sağlamak için aşırı akımlardan ve aşırı voltajlardan kaçınmaktır.

Elektriksel arıza değerleri daima yüksek gerilimlerden veya akımlardan kaynaklanır.

Başka bir konu mekanik olaylardır. Güç elektromekanik olarak dönüştürülüyorsa, sadece elektrik değil mekanik donanım da dikkate alınmalıdır. örnek olarak buhar türbinlerinin düşük frekans nedeniyle mekanik rezonansı verilebilir. Günümüzde elektromekanik koruma cihazları, bir dizi entegre özelliğe sahip mikroişlemci tabanlı röleler ile değiştirilmiştir. Akımlar, voltajlar, hat uzunlukları, transformatörleri dijital forma dönüştürülür. $\mathrm{Bu}$ değerler açma kararlarına ulaşan çeşitli algoritmaların içine girerler. Gelişen benzetim programlarında farklı senaryolar oluşturulabilir. 
Ağdaki koruyucu rölelerin tasarımı ve koordinasyonu için genel kurallar geniş çapta kabul görmüştür:

Seçicilik: Bir koruma sistemi arıza sonuçlarını en aza indirmek için sadece hatalı parçanın bağlantısını kesmelidir(veya arızayı içeren en küçük parça).

Koordinasyon: Bir koruma sisteminin işlevini yerine getirmesi için özen göstermelidir. Oluşabilecek farklı durumlar için röleler ile gereksiz koruma tasarımları değerlendirilip, farklı koruma ilkeleri birleştirilebilir. Örneğin; Hatlar için mesafe ve diferansiyel koruma ilkeleri birleştirilerek kullanılır.

Derecelendirme: Röle koruması sisteminin gereksiz veya yanlış açma yapmaması için röle koruması derecelendirilmelidir. Böylece koruma sisteminin güvenirliği artırılmalıdır.(Geidl, 2005)

Güvenirlik: Röleler yanlış açmalar ile sağlıklı çalışan enerji sistemini gereksiz olarak açmamalıdır. (Öhrström,2003)

Alan Koruması: Röle sistemi arızayı güç sisteminden en küçük alanı ayırarak sistemin geri kalanını etkilemeden koruma işlemini gerçekleştirmelidir. (Öhrström,2003)

Korumak için en basit ağ yapısı radyal sistemlerdir, bu nedenle basit röleler kullanılır (Bergen, Vital,2000). Normalde, zamana bağl1, kademeli aşırı akım koruma, fazlalık (yedekleme korumas1) konusunda kurulur. Halkaların ve örgü 1zgaraların korunması için daha karmaşık röleler kullanılır. Empedans röleleri düşük voltaj akım oranı nedeniyle tetiklenir.

Hatanın hat üzerindeki konumunu belirlemek için ayrıca mesafe röleleri olarak da adlandırılırlar (Jenkins,2000) ( Bergen, Vital, 2000) (Muller, Boog, 1990).

\section{Kısa Devre Gücü ve Arıza Akım Seviyesi}

Arıza akımı seviyesi, arızaların akım veya güç açısından etkisini açıklar. Kısa devre akımı veya (görünür) güç artışı hakkında bir gösterge verir. ( N. Jenkins et al 2000)

Arıza akım seviyesi $\mathrm{i}=1 /$ zth | olarak tanımlanır ( Koeppel. G 2003 ). Burada i nominal akımla ilgili arıza akımıdır ve zth ise hattın thevenin empedansını p.u. olarak gösterir. Burada 1 p.u. anma akımına karşılık gelir.

Kisa devre durumlarında faz-faz veya faz-toprak arızaları normalde operasyonel veya nominal akımdan önemli ölçüde yüksek olan bir aşırı akımla sonuçlanır. $\mathrm{Bu}$ (anlık) aşırı akım korumanın işlevi için çok temel bir önkoşuldur. Rölenin arızayı hızlı algılaması için arıza akımı normal işletme akımından ayırt edilebilir olmalidir.

Koruma rölesinin tetiklenmesi için yüksek hata akımı sağlayan güçlü bir kaynak bulunmalıdır. PV kurulumlarında özellikle dönüştürücüler genellikle yüksek akımı önleyen kontrol cihazları ile donatılmıştır. Özellikle güç elektroniği dönüştürücüler genellikle yüksek akımları önleyen kontrol cihazlarıyla donatılmıştır. Örneğin, bir dağıtım ağının uzak bir kısmı büyük PV kurulumlarında, bir arıza olması durumunda faz akımında neredeyse hiç önemli bir artış olmaz ve bu nedenle de aşırı akım koruma sisteminde arıza tespit edilemez. Arıza akımının genliği, arıza empedansına, faz arızası için de topraklamaya büyük ölçüde bağlıdır.

Şebekeye entegre paralel çalışan farklı üniteler nedeniyle arıza empedansı Zth düşebilir. $\mathrm{Bu}$ nedenle hata seviyesi artar ve bir arıza durumunda beklenmeyen yüksek hata akımları olabilir (Şekil 3). Bu durum çalışan ünitelerin bu koşullara göre tasarlanmaması nedeniyle bu üniteleri zora sokar. 


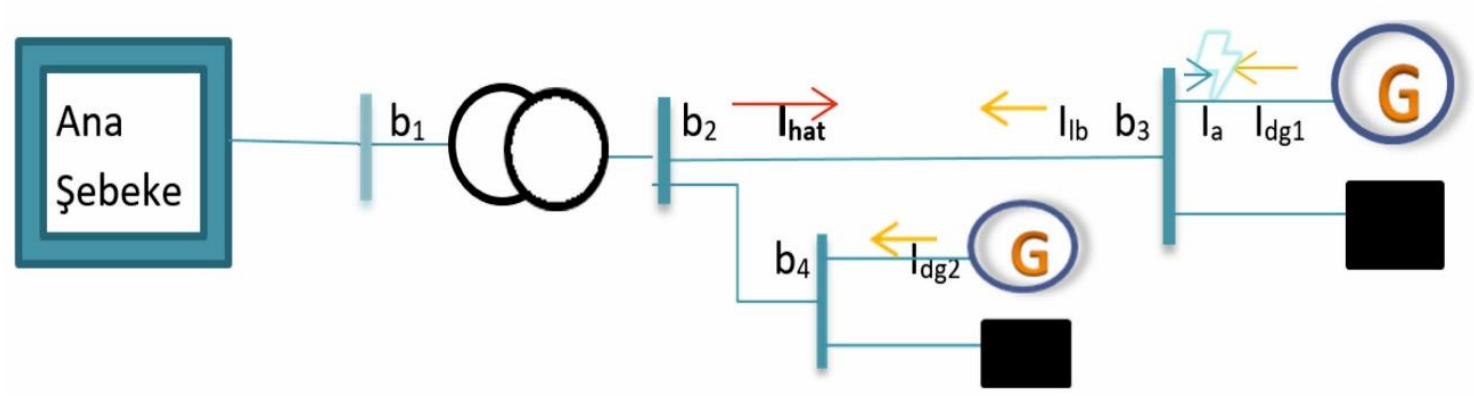

Şekil 3. Kısa devre akımı. Idg embedded generator Ihat ana şebeke akımı

Bara 2 deki röle sadece $I_{h}$ akımını ölçer, röle gerçek arıza akımını ölçemediği için hatalı çalışır.

Aşırı akım rölesinin zamanında devreye girmemesi yüksek empedanslı sistemlerde ciddi problemler oluşturur. Diğer yandan bara 2 de meydana gelen ariza durumun da Lokal jeneratörler arıza akımını etkiler. Kısa devre durumları incelendiği zaman geleneksel sistemden farklı olarak DG lerin kisa devre akımın genliğini, yönünü ve süresini etkilediği görülür.

\section{Şebeke Koruma Yöntemleri (Anti- Islanding)}

Adalaşma durumunun DG koruma sistemi tarafindan tespiti için aktif ve pasif yöntemler oluşturulmuştur (Şekil 4). Pasif metotlarda sistem verileri pasif yöntemlerle takip edildiğinden bu yaklaşımın enerji güç kalitesi üzerinde olumsuz etki barındırmaz. Aktif koruma ise daha doğru sonuçlar oluştursada, sisteme bazı sinyaller enjekte ettiklerinden küçük oranlarda da olsa güç kalitesini olumsuz etkileyebilir.

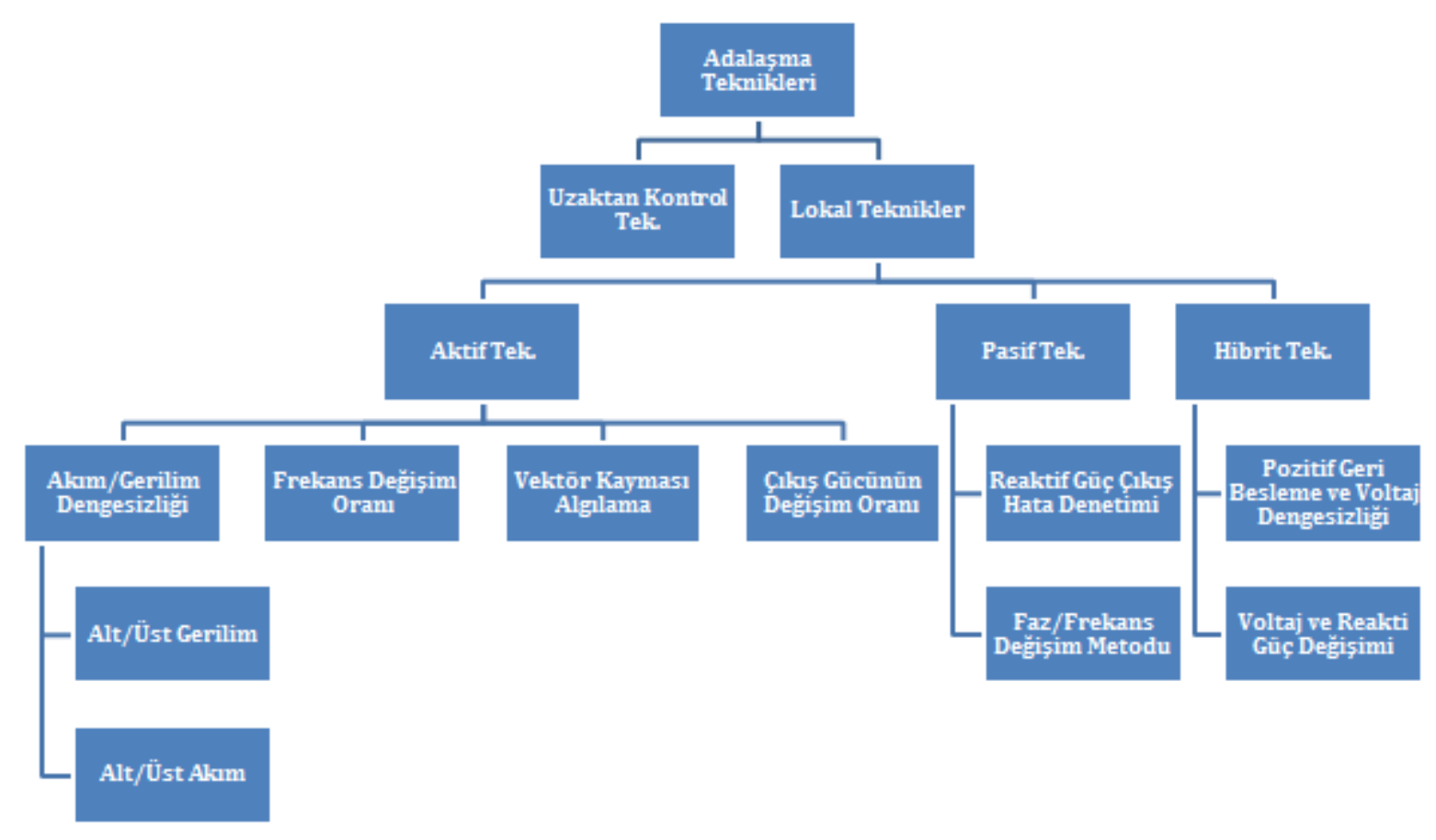

Şekil 4. Şebeke Koruma Yöntemleri (Anti-Islanding) 
Solar (PV) sistemler için de geçerli olan adakarşıtı modunu da kapsayan uluslararası test standartları belirlenmiştir (Friedman. N.R. 2002) (Ye Ez et all 2003) (Geidl M. 2005) (Electricity Council G59 1985). Türkiye' de geçerli olan bu standardlarda, sıradışı şebeke durumlarında solar (PV) invertör tepkileri ve fonksiyonları belirlenmiştir.

\section{Pasif Koruma Yöntemleri}

Pasif Koruma yöntemleri aşağıdaki gibidir.

1. Voltaj-Akım-Frekans Dengesizlik Rölesi

2. Vektör Dalgalanma Tespit Rölesi

3. RoCoP Çıkıș gücünün değișim oranı
Rölesi

4. RoCoF Frekansın değişim oranı Rölesi

\section{Bulgular ve Yorum}

Çalıșmada Adalașma durumu MATLAB Simulink programı ile simüle edilip, farklı arıza durumlarına göre oluşturulan seneryolar sonucunda yük ile pv sistemin farklı durumlarına göre (lokal yükün yerel santral gücünden fazla ve az olma durumları) (Şekil 5, Şekil 7 ve Şekil 9) ana şebekenin ayrılması sonucunda oluşan adalaşmanın simülasyon sonuçları Şekil 6, Şekil 8 ve Şekil 10'da görülmektedir.

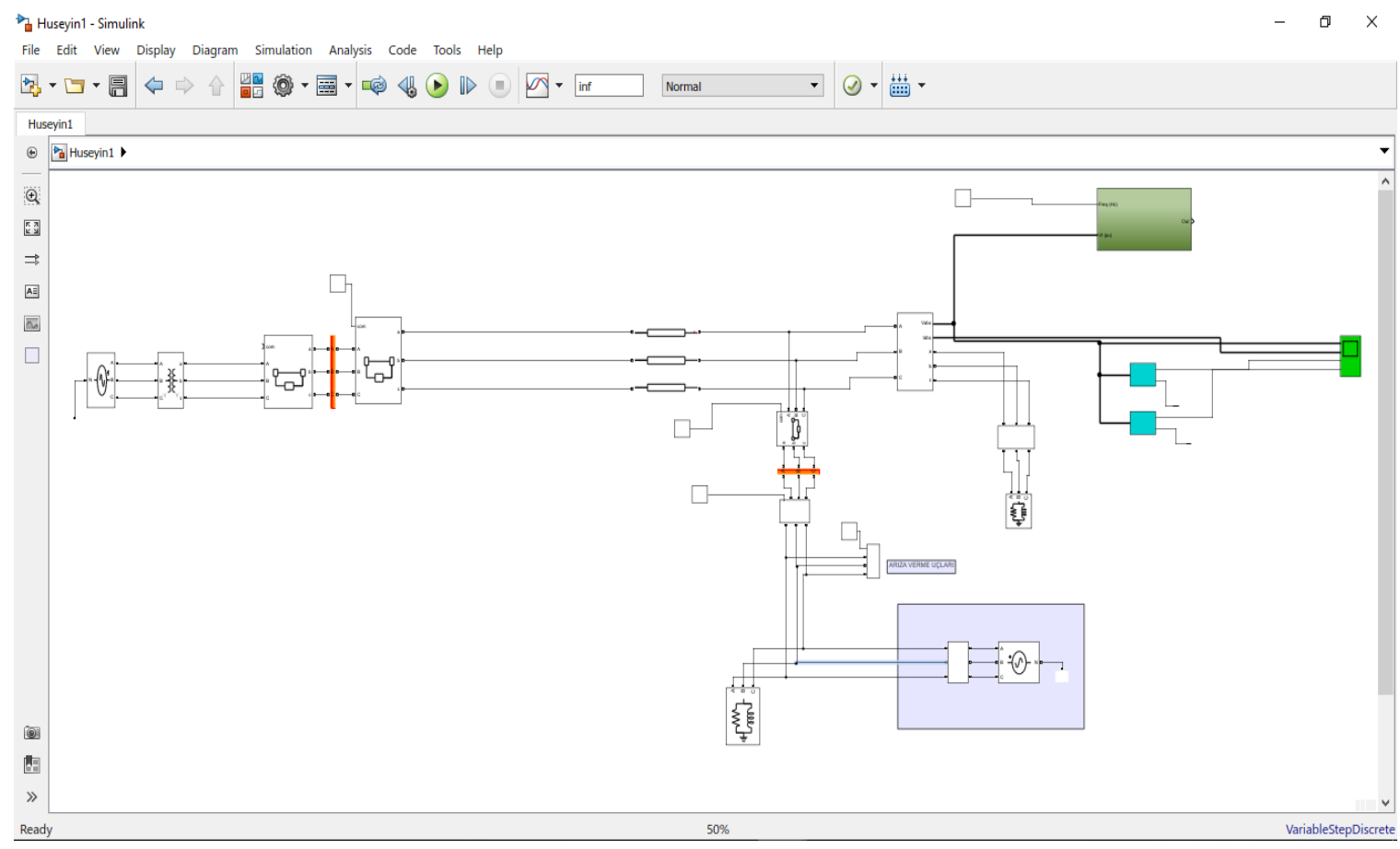

Şekil 5. Şebeke ve DES in birlikte çalışması MATLAB SIMULINK 


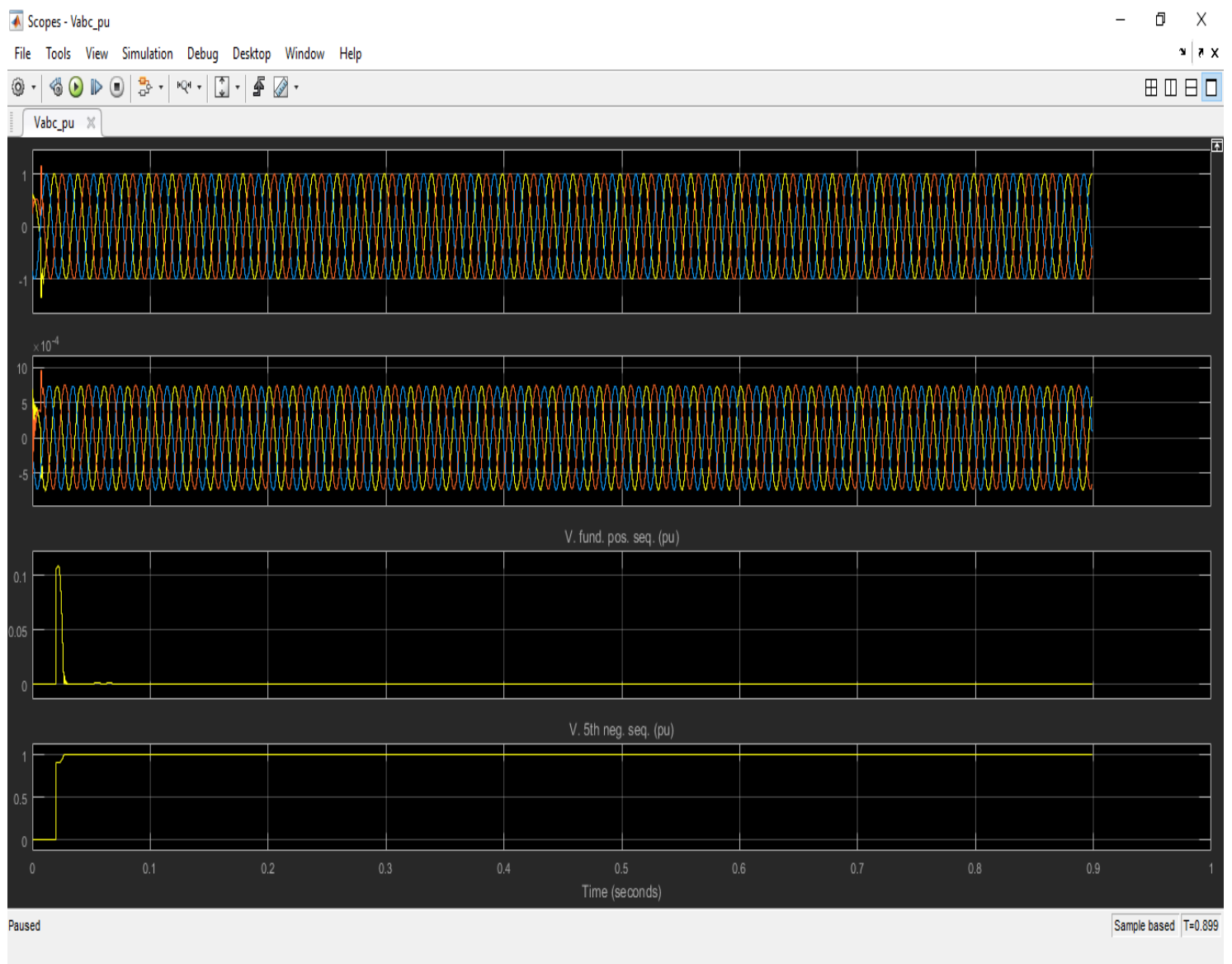

Şekil 6- Şebeke ve DES in Birlikte Çalışırken Akım Gerilim Grafiği MATLAB SIMULINK

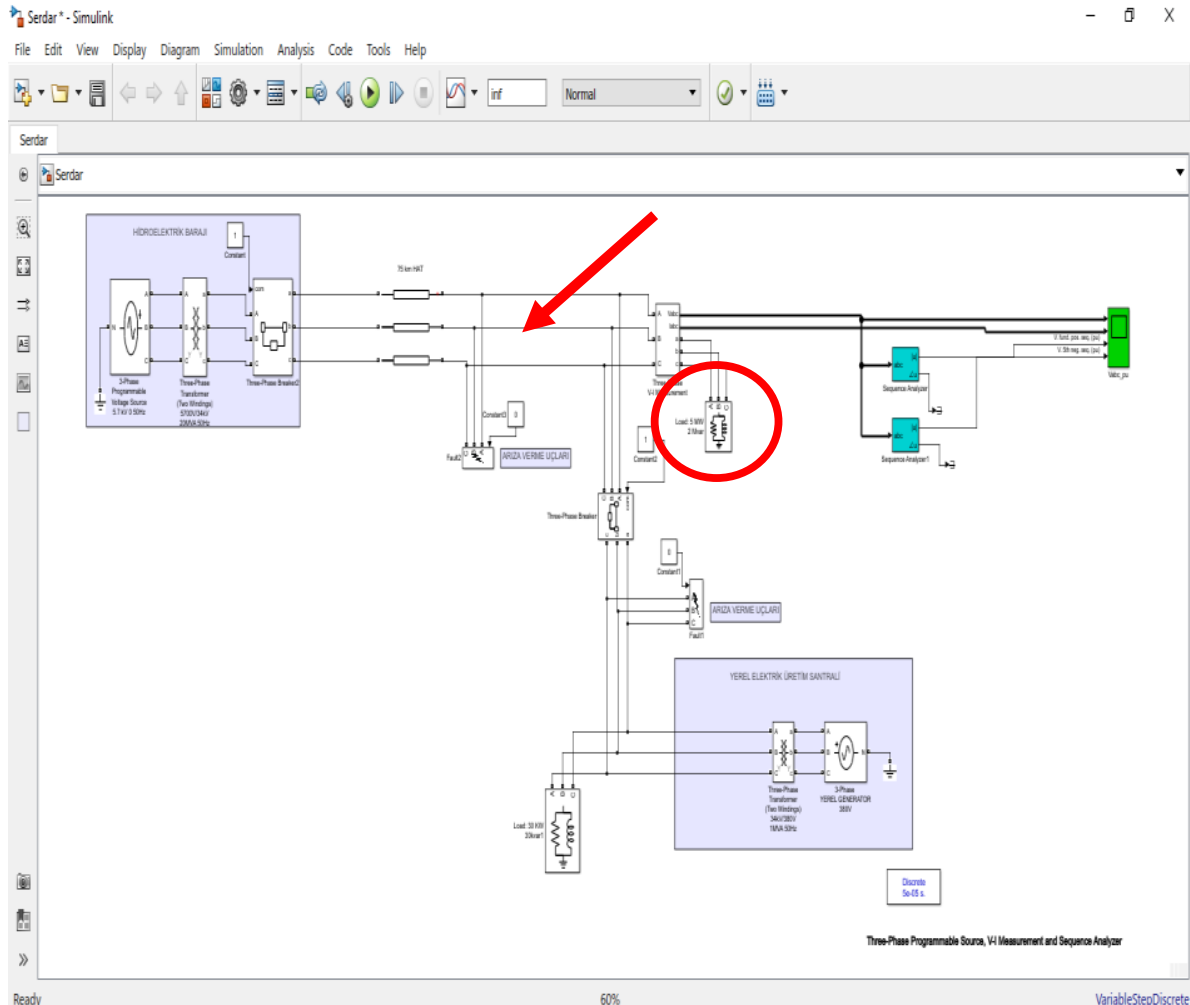

Şekil 7- 3 Fazlı yüklü Devre üzerinde arıza noktası 


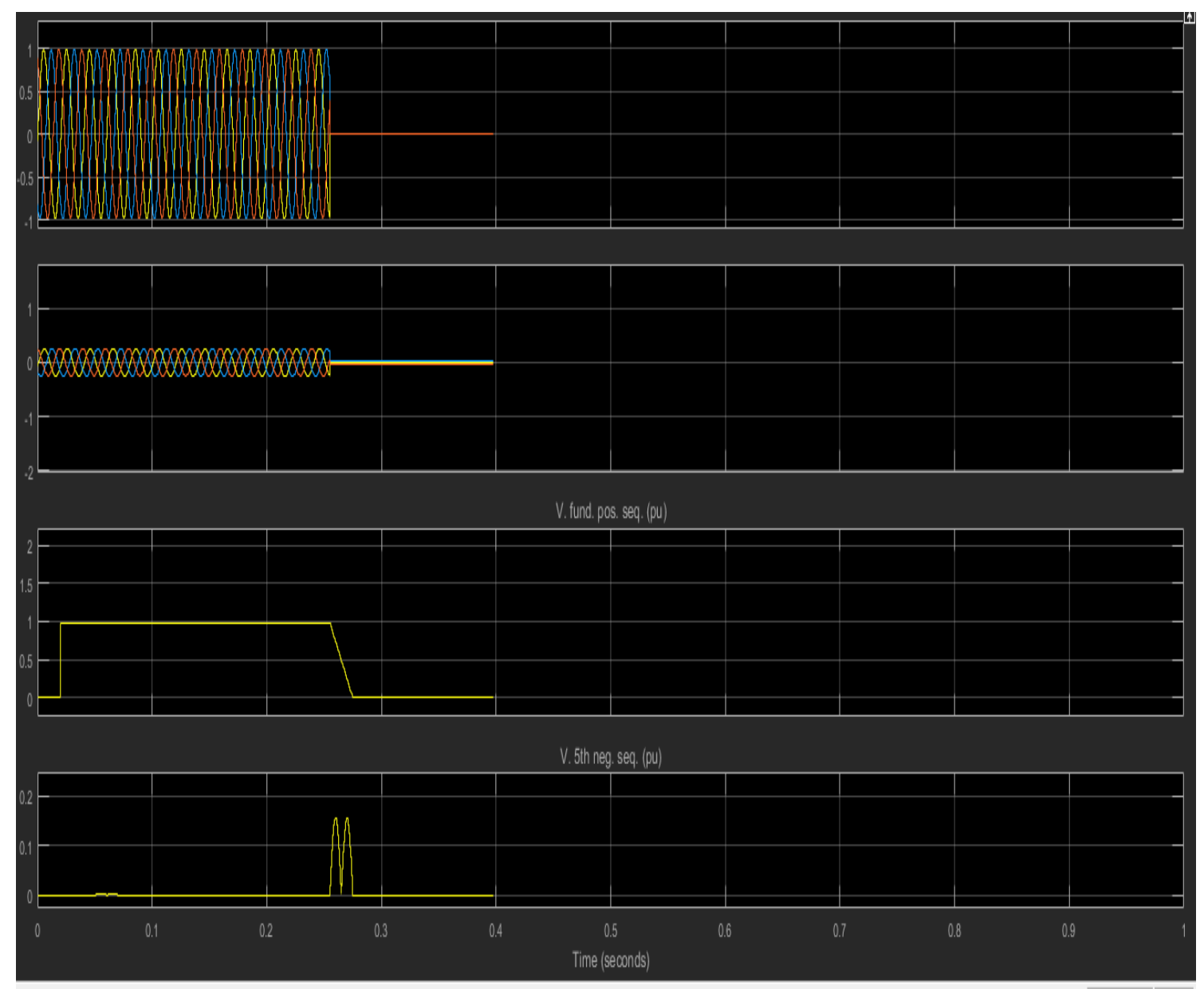

Şekil 8- Orta Gerilim Ana Şebekede de 3 Faz Toprak Arızası meydana gelmesi ve Fazla Yük ile ölçüm

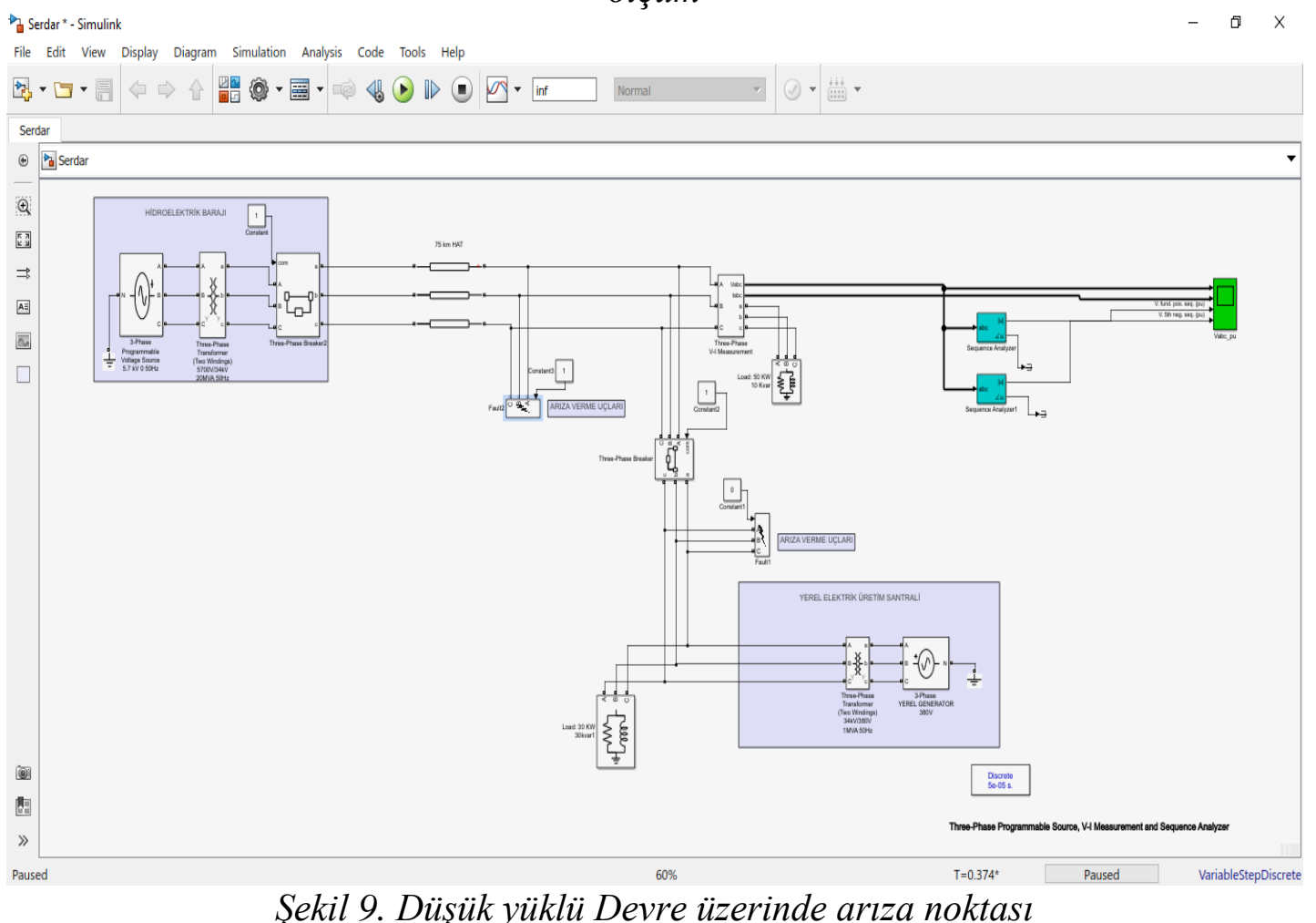




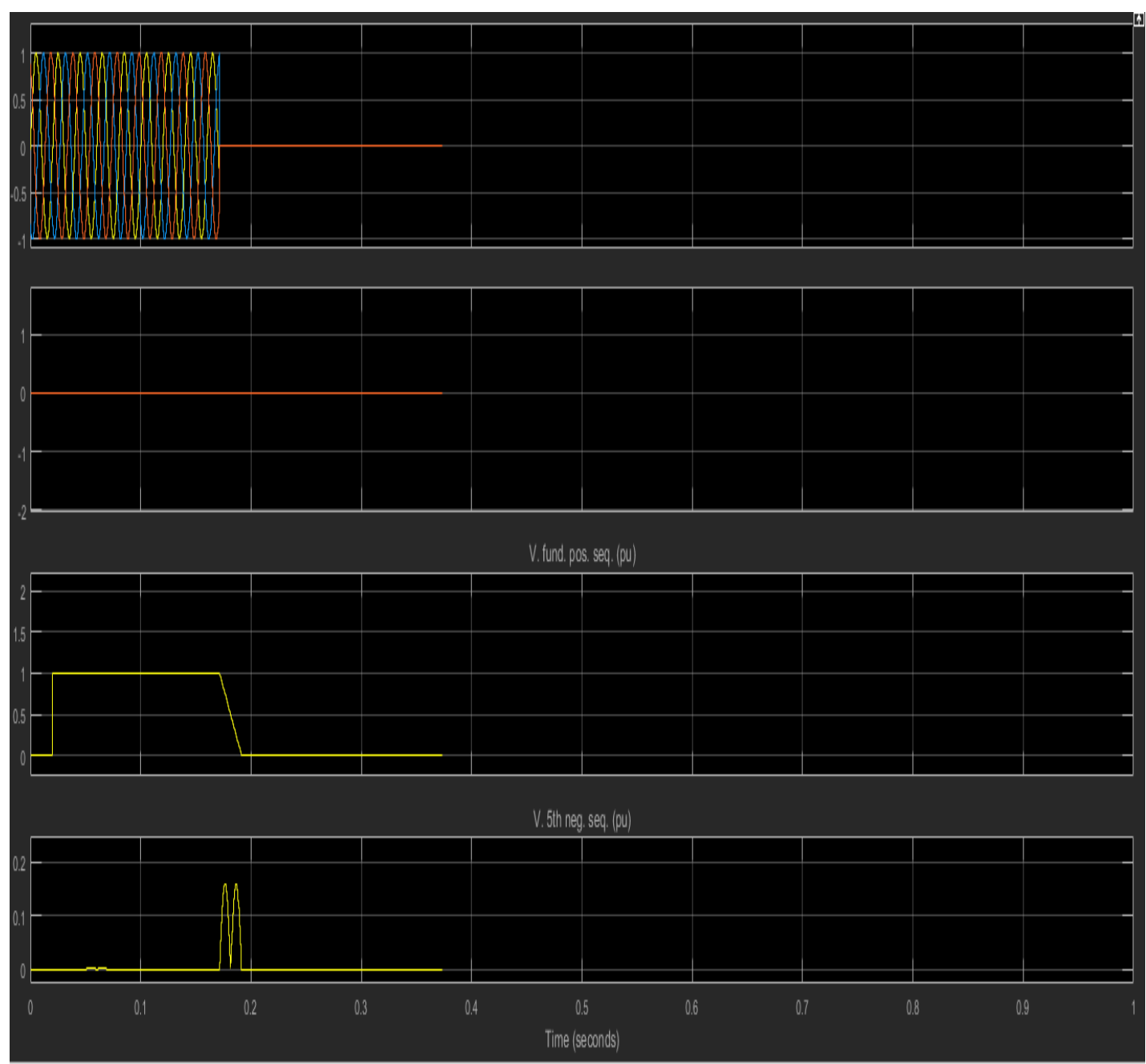

Şekil 10- Orta Gerilim Ana Şebekede de 3 Faz Toprak Arızası meydana gelmesi DÜŞÜK Yük ile ölçüm

\section{Sonuçlar ve Tartışma}

İletim seviyesinde ana şebeke ile paralel çalışan Dicle Üniversitesi Güneş Enerji Santrali olası 3 faz arızaları sonucunda meydana gelecek adalaşma örneklerindeki, farklı akım-gerilim değerleri Matlab Simulink programiyla tasarlanarak grafiklerde bu arızalara ait akım ve gerilim değerleri elde edilmiştir. Elde edilen bu değerlere göre koruma sistemi oluşturulmuştur.

$\mathrm{Bu}$ çalışmada, şebekeye entegre olan Dicle üniversitesi Güneş Enerji Santralinin Matlab simülasyonu ile oluşturulan sistemde, meydana gelecek olası arızalar sonucunda oluşabilecek adalaşma problemi tespit edilmiş ve oluşacak bu probleme karşın mutlaka etkili bir koruma sisteminin oluşturulması önerilmiştir. Buna ek olarak Dicle Üniversitesi Güneş Enerji Santrali
Mühendislik Fakültesini ana şebekeyle paralel çalışırken beslediği düşünerek üretimden yükün az olduğu ve üretimden yükün fazla olduğu senaryoları oluşturulmuş ve buna göre akımgerilim değerleri elde edilmiştir.

Dünyadaki gelişen bireysel yerel enerji santralleri için, ülkelerin kendi enerji sistemlerinin karakteristik değerlerine göre koruma sistemleri oluşturulmaktadır. $\mathrm{Bu}$ bağlamda öncü bir grup liderliğinde gerekli ARGE çalışmaları yapılıp Türkiye' nin kendi koruma standartlarını oluşturması kaçınılmazdır.

Ülkemizde sayıları hızla artan dağıtık üretim santrallerinin enerji kalitesine ve maliyetine olumsuz etki sunmaması için kendi sistemine göre kurallar ve koruma sistemleri dizayn 
edilmelidir. $\mathrm{Bu}$ nedenle özellikle röle mühendislerine ve bu konuda çalışan araştırmacılara çok iş düşmektedir. $\mathrm{Bu}$ çalışmaların belli bir koordinasyon gurubu önderliğinde hızlıca oluşturulması olası negatif problemleri çözmek için gereklidir.

\section{Kaynaklar}

Barker P.P. and Mello R.W.. De Determining the impact of distributed generation on power systems. I. Radial distribution systems. In IEEE Power Engineering Society Summer Meeting, volume 3, pages $1645-1656$ vol. 3, 2000.

Clark H K \& Feltes J W, "Industrial and Cogeneraiton Protection Problems Requiring simulation." IEEE Trans. on industry Applications, Vol.21,No. 1, pp 69-80, Jan./Feb 1985

Dağıtım tesislerine bağlanacak üretim santralleri için fider kriterleri ,TEDAŞ

Electricity Association, "Engineering Technical Report" No.113 revision 1995

Electricity Council, "Notes of Guidance fort the Protection of Private Generating Sets for Operation in Parallel with Electricity Board Distribution Networks." Engineering Recommendation G59, London, June 1985.

Elektrik Piyasası Dağıtım Yönetmeliği, www.epdk.gov.tr

Elektrik Piyasası Lisans Yönetmeliği, www.epdk.gov.tr

Elektrik Piyasası Şebeke Yönetmeliği, www.epdk.gov.tr

Elektrik Piyasasında Dağıtım Sisteminde Sunulan Elektrik Enerjisinin Tedarik Sürekliliği, Ticari ve Teknik Kalitesi Hakkında Yönetmelik, www.epdk.gov.tr

Friedman.N.R. Distributed energy resources interconnection systems: Technology review and reserach needs. Technical Report NREL/SR560-32459, National Renewable Energy Laboratory, 2002

Geidl M. Power Systems Laboratory Swiss Federal Institute of Technology (ETH) Zurich,

GUO-KIANG HUNG ET AL: "Automatic phase-shift method for islanding detection of grid-connected photovoltaic inverters", IEEE Transactions on Energy Conversion., vol. 18, no. 1, 1 March 2003

Kane P. O' and Fox. B. Loss of mains detection for embedded generation by system impedance monitoring. In Developments in Power System Protection, Sixth International Conference on (Conf. Publ. No. 434), pages 95-98, 1997.

Moore P J, Carranza R D \& Johns A T, “A New Numeric Technique for High Speed evalution of Power system Frequency." IEE proc. On Generation, Transmission \& Distribution, 141,5,1994,529-536

Nguyen C T, "A New Technique for Rapid Tracking of Frequency Deviations Based on Level Crossings", IEEE Trans. on Power Apparatus and System,Vol.PAS103,No.8,Aug. 1984,PD.2230-2237.

Nichols N, "The Electrical Considerations in Cogeneration." IEEE Trans. on Industry Applications, Vol.21,No.4, pp 754761,May /june 1985.

Piyasasında İletim ve Dağıtım Sistemlerine Bağlantı ve Sistem Kullanımı Hakkında Tebliğ, www.epdk.gov.tr

Powell L J, "An industrial View of Utility Cogeneration protection Requirements". IEEE Trans on IA-24. Pp 75-85, Jan/Feb 1988.

Redfern M.A., Barrett J.I., and Usta O.. A new loss of grid protection based on power measurements. In Sixth International Conference on Developments in Power System Protection (Conf. Publ. No. 434), pages 91-94, 1997.

Salman S.K., King,D.J. and Weller G.. New loss of mains detection algorithm for embedded generation using rate of change of voltage and changes in power factors. In IEE Seventh International Conference on Developments in Power System Protection, pages 82-85, 2001. 98

Usta Ö, Erdoğan Z ve Bayrak M "Yerel Elektrik Santrallerinde Koruma ve Kontrol Problemleri" 6. Ulusal Kongre Bursa, 1995

Waine S A, Tindall C E \& Clay W, "Frequency Tracking for Power Control." IEE Proc. On Generation, Transmission and 
distribution, Vol. 133, Part C, No.2, Mar.1986,pp. 95-98

Warin J W, 'Loss of Mains Protection.' ERA Conferance: Circuit protection for Industrial and Commercial Installation, London 1990.

Warin J. W. Ailen W.H.,1981, Loss of Mains Protection, California Edison Company, 1981.

Woodbury F A, "Grounding Considerations in Cogeneration." IEEE Trans. on Industry
Applications, Vol. 21, No. 6, pp 15231532,Nov./Dec. 1985.

Woodworth M "Co-generator(CHP) view point" (Engineering Manager, Combined Power Systems), 15/10/1996

Ye Z. et al Testing of GE universal interconnection device. Technical Report NREL/TP-560-34676, National Renewable Energy Laboratory, 2003. 


\section{A new approach to rate of change of frequency relay preventıng islandıng in local power}

\section{Extended Abstract}

With the amendment within the scope of Article 14 of the Electricity Market Law dated 14/3/2013 and numbered 6446, many local power plants would be installed or will be established and operational in parallel with the electricity networks. With the recent amendments to the law, the establishment and commissioning of many local power plants are continuing. In addition to the major contribution of these power plants to energy production, they create various problems for technical personnel and other consumers during their parallel operation with the grid. In this study, firstly, the connection of Dicle University Solar Power Plant with Main Grid was modeled in Matlab simulation environment and data obtained against possible failures were observed. Later, different scenarios that will occur in case the Power Plant, which works in parallel with the Main Network, feeds the Faculty of Engineering are designed in the simulation environment and the results of these simulations are evaluated.

Today, population growth and developments in electrical-electronic technology increase the dependence of the societies in the world and our country on electrical energy. The depletion of fossil fuels and environmental problems have encouraged all countries in the world to use alternative energy sources. These developments have led to the restructuring of traditional electrical energy systems.

Distributed Generation (DG) or Embedded Generation (Individual Local Power Plants embedded in the traditional system) is a concept connected with the traditional network system due to the high number and connection points. Individual local generation plants are defined as Distributed Generation plants that are connected in parallel with the Main grid at the connection points. DG plants cause double-sided load flow as opposed to the traditional system and become part of the interconnected system.

Active and passive methods have been established for the determination of the islanding state by the distributed generation protection system. Since passive methods are followed by outside data from relays, this approach has no negative effect on energy power quality. Active protection, on the other hand, may produce a more accurate result, however, because it injects some signals into the system, it may adversely affect power quality, even in small amounts.

This paper presents modeling and simulation of the grid-connected Dicle University $P V$ generation system under MATLAB/Simulink. Firstly, In this study, possible fault conditions are designed by Matlab simulation of Dicle University Solar Power Plant integrated to the grid. Different cases are simulated, and the results have verified the validity of models and control schemes.

The current, voltage results obtained from different systems created with Matlab Simulink program were evaluated for the islanding samples that will occur as a result of the parallel operation of the Dicle University Solar Power Plant at the transmission level and possible 3 phase failures.

Keywords: Distributed Generation, Rocof, Islanding , Embedded Generation. 